\title{
O tempo da justiça criminal \\ Estados Unidos e Brasil em uma perspectiva comparada*
}

\author{
The duration of criminal justice \\ USA and Brazil under a comparative perspective
}

Ludmila Ribeiro**

\begin{abstract}
Resumo: A proposta deste artigo é apresentar pesquisas já realizadas sobre os determinantes do tempo da justiça criminal nos Estados Unidos da América e no Brasil dentro de uma perspectiva comparada. Ao contrário do que ocorre nos Estados Unidos, na realidade brasileira, pesquisas sobre o tempo da justiça criminal ainda são muito pouco realizadas. Assim, reunir os estudos efetuados em ambas as localidades pode auxiliar na melhor compreensão do problema, bem como apontar questões que, apesar de relevantes, ainda não foram abordadas pelas análises realizadas no âmbito nacional.
\end{abstract}

Palavras-chave: justiça criminal; tempo; estudos comparativos

\begin{abstract}
Using a comparative perspective, the present paper examines contemporary research on the determinants of the length of criminal justice in the United States of America and Brazil. In opposition of this field in United States of America, in Brazil research on the criminal justice system is not well performed. In this sense, comparing these two lines of research will allow to analyze the possibilities and limitations that have not yet been addressed by national analysis.
\end{abstract}

Keywords: criminal justice; time; comparative studies

\footnotetext{
Uma primeira versão deste estudo foi apresentada no XXVIII Congresso Internacional da Associação de Estudos Latino-Americanos (Lasa), realizado no Rio de Janeiro de 11 a 14 de junho de 2009. Agradeço aos colegas do grupo sobre reforma do Judiciário as críticas e sugestões, indispensáveis para a construção da versão final deste artigo. Agradeço ainda aos pareceristas as valiosas contribuições para esta análise.

** Doutora em Sociologia pelo Instituto Universitário de Pesquisas do Rio de Janeiro (Iuperj). Atualmente, pesquisadora do Centro de Pesquisa e Documentação de História Contemporânea do Brasil (CPDOC), da Fundação Getulio Vargas (FGV). <ludmila.ribeiro@gmail.com>.
}

\begin{tabular}{|c|c|c|c|c|c|}
\hline Civitas & Porto Alegre & v. 10 & n. 2 & p. 309-329 & maio-ago. 2010 \\
\hline
\end{tabular}




\section{Introdução}

Neste artigo, o objetivo é apresentar as pesquisas já realizadas sobre os determinantes do tempo da justiça criminal nos Estados Unidos da América (EUA) e no Brasil dentro de uma perspectiva comparada.

$\mathrm{O}$ sistema de justiça criminal norte-americano foi escolhido como base de comparação por possuir, simultaneamente, semelhanças estruturais com o Brasil (estruturas políticas e características capitalistas) e distinções em termos de seus modelos jurídicos de controle social (Kant de Lima, 1995). Soma-se a isso o fato de a realidade norte-americana apresentar o maior número de pesquisas sobre o tema central deste artigo, podendo, portanto, ser considerada um cenário no qual o conhecimento acerca dessa área se encontra razoavelmente consolidado.

Para que as metodologias e os resultados produzidos nessa localidade possam ser incorporados ao Brasil sem problemas ou distorções em termos de seu significado, faz-se necessário apresentar os padrões de funcionamento desse sistema de justiça criminal e os pressupostos para a realização do método comparado.

Com base na análise comparada proposta, pretende-se responder às seguintes questões: em que medida os estudos realizados no Brasil apontam para o fato de que o tempo da justiça criminal é o resultado combinado das mesmas variáveis que explicam o tempo de processamento nos EUA? Em que medida os estudos que têm como foco o sistema brasileiro foram ou não capazes de incorporar todas as dimensões analisadas em pesquisas sumarizadas sobre esse fenômeno realizadas nos EUA? Será que a inclusão de novas dimensões - relevantes para a compreensão do tempo de processamento no âmbito do sistema de justiça criminal dos EUA - nas análises relacionadas a esse mesmo objeto no Brasil pode lançar novas luzes para o entendimento do fenômeno? Ou será que o tempo de processamento deve ser entendido apenas como um indicador da tradição jurídica de determinada localidade?

Assim, para a realização dessa análise, além desta introdução, o artigo encontra-se estruturado em quatro seções. Na primeira, tem-se a apresentação da metodologia comparada. Em seguida, focam-se as especificidades de cada realidade, iniciando pela identificação dos elementos que parecem explicar o tempo da justiça criminal nos EUA. Na terceira seção, é feita a revisão das pesquisas que abordam os determinantes do tempo de processamento no sistema de justiça criminal brasileiro. Por fim, os resultados de ambas as revisões são problematizados com o objetivo de se verificar se o que parece explicar o tempo da justiça criminal em uma localidade é também o que explica 
o tempo da justiça criminal na outra. Nessa última seção, são discutidos os caminhos que a ciência social brasileira ainda tem de percorrer para acumular um conhecimento mais substantivo sobre a questão do tempo do sistema de justiça criminal.

\title{
Comparação entre os sistemas de justiça criminal: limites e potencialidades
}

O método comparativo utilizado neste artigo pode ser definido como aquele que busca explicar determinado fenômeno com base nas semelhanças e nas diferenças apresentadas por duas séries de natureza análoga tomadas de meios sociais distintos (Bloch apud Theml e Bustamante, 2007: 3). A utilidade desse método, quando aplicado aos estudos sobre o funcionamento do sistema de justiça criminal, está relacionada ao fato de mostrar como,

\begin{abstract}
dependendo do quadro jurídico mais geral, instituições semelhantes podem ter diferentes papéis no que diz respeito à justificação e posicionamento do sistema jurídico frente a modelos e instituições "leigos" de controle social, em diferentes sociedades e culturas. O contraste pode mostrar como diferentes estratégias de reprodução do campo do Direito são reciprocamente determinadas pelos processos de reprodução e mudanças sociais da sociedade como um todo (Kant de Lima, 1995: 12).
\end{abstract}

A correta contextualização de dada temática em uma perspectiva comparada permite, portanto, de um lado, dimensionar, com mais objetividade, proximidades e afastamentos, o problema a ser abordado e, de outro, tornar mais transparente, pela força do contraste, a realidade de cada país (Loundo e Misse, 2003). Assim, para início da análise comparada, faz-se indispensável contextualizar os modelos de operação de cada um desses sistemas de justiça criminal, compreendendo como seus arranjos estruturais se acoplam à cultura da sociedade em que estão inseridos (Pakes, 2004).

Esse é o primeiro procedimento a ser realizado, pois qualquer comparação deve ter cuidado com a tradição jurídica em questão, devendo tal termo ser entendido como um conjunto de atitudes profundamente arraigadas, historicamente condicionadas, sobre a natureza do direito, sobre o papel do direito na sociedade, sobre a organização de um sistema legal. Ou seja, trata-se de um conjunto de práticas que caracterizam o direito em determinada sociedade (Merryman, 1969). As tradições jurídicas em análise aqui são a common law e a civil law.

O sistema de justiça criminal norte-americano, filiado à tradição da common law, pode ser entendido como aquele no qual o direito é criado ou aperfeiçoado 
pelos juízes: uma decisão a ser tomada em um caso depende das decisões adotadas nos casos anteriores e afeta o direito a ser aplicado a casos futuros. Nesse sistema jurídico, a análise do caso se faz valendo-se de determinados precedentes, e não por meio de diplomas legais que regulam determinada questão. Quando não existe um precedente, os juízes possuem autoridade para criar o direito, estabelecendo um precedente (Siegel e Senna, 2007).

O sistema de justiça criminal brasileiro, filiado à tradição da civil law, é de origem romano-germânica. Dentro de seu arcabouço institucional, todas as controvérsias devem ser dirimidas de acordo com os diplomas legais que regem a questão. Dessa forma, casos semelhantes podem implicar decisões diferentes, visto que a solução anterior de um caso não produz vinculação da matéria para a decisão de casos subsequentes. Nesse sistema, a administração da controvérsia se dá pela interpretação do diploma legal, e não pela vinculação de precedentes; a interpretação dos códigos legais só pode ser realizada por quem possui autoridade para tanto dentro do sistema de justiça criminal. Essa interpretação é direcionada pelos processos de inquirição, utilizados como melhor forma de estabelecer a verdade e de evitar conflitos na sociedade (Kant de Lima, 1995).

Outra forma de explicar as diferenças entre os dois sistemas é a possibilidade de realização de acordos. O sistema da civil law admite apenas um tipo de processamento e de desfecho, tal como estabelecido pelas leis que regem a controvérsia. Em uma realidade como essa, os acordos de abreviação do fluxo processual não são possíveis, dado que não são amparados pelas normas formais que regulam a atividade adjudicatória (Sapori, 2006: 769). Já o sistema da common law admite que o caso seja encerrado por meio de acordos entre os envolvidos. Os acordos são legítimos porque o contraditório, ainda que previsto em lei, deve ser reservado apenas aos casos em que defesa e acusação não sejam capazes de estabelecer um consenso sobre a verdade dos fatos (Sica, 2006).

Outra diferença importante diz respeito ao papel do juiz em cada tradição jurídica. Segundo Werneck Vianna (1996: 272), nos países filiados à tradição da common law, o direito não seria apenas a emanação da atividade do poder soberano, na medida em que constaria igualmente do direito precedente, acumulado em fases históricas anteriores - as "leis comuns" à Europa. Tal direito demanda, portanto, a figura do jurista intelectual, treinado na pesquisa e na técnica jurídica e, por isso, capaz de interpretar a cada situação de que maneira o precedente pode ser aplicado. Contrariamente, nos países filiados à tradição jurídica da civil law, o Judiciário se encontra atrelado às normas elaboradas pelo Legislativo, devendo o jurista dessa tradição ser apenas capaz 
de aplicar as regras técnicas e, com isso, garantir previsibilidade e certeza jurídica à administração do direito. Nesse cenário, os juízes são destituídos da antiga aura que lhes vinha da função de intérpretes especializados da tradição e convertidos em prisioneiros dos códigos legais.

Por outro lado, como esses sistemas integram sociedades distintas, suas ossaturas institucionais também são diversas. Os fundamentos de operação e a forma de produção dos resultados são diferenciados em ambas as realidades; e, em certa medida, em razão dessas diferenças estruturais e estruturantes, pode ser que o tempo de processamento do delito seja distinto e influenciado pelas categorias estruturais que orientam a constituição e o funcionamento de cada sistema.

No Brasil, a operação do sistema de justiça criminal é fundada na desconfiança - considerando que o réu pode mentir em seu benefício ${ }^{1}$ e que, para sua mentira ser descoberta, tudo o que ele disser deve ser documentado ou referendado por testemunhas. Evidentemente, todo esse processo de documentação tem um custo, em termos do tempo de processamento, o que não ocorre em sistemas nos quais não há preocupação com o registro, como nos EUA.

No contexto norte-americano, a operação do sistema de justiça criminal é fundada na confiança de que o réu dirá a verdade - para que seu processo seja rápido, e sua pena a mais branda possível. Como nessa localidade não há uma preocupação excessiva com a documentação, o tempo de processamento tende a ser, naturalmente, menor. Exatamente por isso não é possível comparar esse fator entre o Brasil e os EUA e dizer que sistema é mais eficiente, visto que o tempo de processamento é naturalmente distinto. No entanto, é possível comparar os determinantes do tempo na medida em que variáveis semelhantes podem ter efeitos diferenciados e, com isso, até mesmo, destacar o que é produto do saber local e o que pode ser entendido como fenômeno afim em ambas as localidades.

Para que essa comparação seja realizada de maneira adequada, em um primeiro plano, é preciso destacar as características de cada sistema de justiça criminal. De maneira bastante simplificada, no Quadro 1 a seguir, é possível visualizar as diferenças especialmente em razão de oito variáveis: 1) tradição jurídica a que o sistema se filia; 2) origem do sistema; 3) forma de construção do processo criminal pelas organizações que compõem o sistema; 4) forma de construção da verdade; 5) validade da palavra do réu; 6) papel das testemunhas; 7) fim maior do processamento; 8) possibilidade de julgamento pelo júri.

1 Como bem salienta Kant de Lima (1995), no Brasil, ao se assegurar constitucionalmente o direito de o acusado não se autoincriminar (direito ao silêncio), não se criminaliza a mentira dita pelo réu em sua defesa. 


\section{Quadro 1: Principais diferenças entre os sistemas de justiça criminal norte-americano e brasileiro}

\begin{tabular}{|c|c|c|}
\hline Característica & Sistema norte-americano & Sistema brasileiro \\
\hline $\begin{array}{l}\text { Tradição jurídica a } \\
\text { que o sistema se filia }\end{array}$ & $\begin{array}{l}\text { Common law: vigência do sistema } \\
\text { acusatório, no qual os atos } \\
\text { praticados são públicos, para que } \\
\text { o acusado possa se defender com } \\
\text { maior amplitude, uma vez que tem } \\
\text { conhecimento de todos os dados que } \\
\text { circundam a situação; o Estado deve } \\
\text { tutelar o interesse desse indivíduo. }\end{array}$ & $\begin{array}{l}\text { Civil law: vigência do sistema } \\
\text { inquisitorial, em que a averiguação } \\
\text { dos fatos deve ser efetuada de forma } \\
\text { sigilosa, a fim de evitar exposição } \\
\text { do indiciado e retaliações ao } \\
\text { denunciante. }\end{array}$ \\
\hline Origem do sistema & $\begin{array}{l}\text { Popular: acordo entre os indivíduos } \\
\text { acerca das melhores regras para a } \\
\text { administração da justiça. }\end{array}$ & $\begin{array}{l}\text { Hierárquica: reflexão iluminada } \\
\text { daqueles que possuem conhecimento } \\
\text { legal e, por isso, podem dizer } \\
\text { quais são as melhores regras para a } \\
\text { administração da justiça. }\end{array}$ \\
\hline $\begin{array}{l}\text { Forma de construção } \\
\text { do processo criminal } \\
\text { pelas organizações } \\
\text { que compõem o } \\
\text { sistema }\end{array}$ & $\begin{array}{l}\text { Não documentação: todos os fatos } \\
\text { e circunstâncias, conhecidos ou não } \\
\text { pelas partes, podem ser trazidos a } \\
\text { julgamento. }\end{array}$ & $\begin{array}{l}\text { Documentação: apenas o que está } \\
\text { formalmente escrito e é previamente } \\
\text { conhecido por ambas as partes pode } \\
\text { ser trazido a julgamento. }\end{array}$ \\
\hline $\begin{array}{l}\text { Forma de construção } \\
\text { da verdade }\end{array}$ & $\begin{array}{l}\text { Consenso entre acusação e defesa: } \\
\text { o processo é um direito do indivíduo } \\
\text { para se defender de uma acusação } \\
\text { que lhe é feita pelo Estado. }\end{array}$ & $\begin{array}{l}\text { Contraditório entre acusação e } \\
\text { defesa: o processo é um dever do } \\
\text { Estado e, por isso, deve ocorrer de } \\
\text { acordo com as regras previamente } \\
\text { estabelecidas nos diplomas legais. }\end{array}$ \\
\hline $\begin{array}{l}\text { Validade da palavra } \\
\text { do réu }\end{array}$ & $\begin{array}{l}\text { Confiança na palavra do réu: este } \\
\text { não poderá mentir porque se encontra } \\
\text { sob juramento. }\end{array}$ & $\begin{array}{l}\text { Desconfiança na palavra do réu: } \\
\text { este não se encontra obrigado a gerar } \\
\text { prova contra si próprio e, por isso, não } \\
\text { precisa confessar, e pode ainda mentir } \\
\text { sobre os fatos sem ser processado por } \\
\text { perjúrio (art. V, LXIII, da CF/88). }\end{array}$ \\
\hline $\begin{array}{l}\text { Papel das } \\
\text { testemunhas }\end{array}$ & $\begin{array}{l}\text { Subsidiário: provas materiais e } \\
\text { confissão do réu são mais importantes } \\
\text { do que os depoimentos das } \\
\text { testemunhas. }\end{array}$ & $\begin{array}{l}\text { Preponderante: apesar de o Código } \\
\text { de Processo Penal estabelecer que } \\
\text { não há hierarquia entre as provas, } \\
\text { as testemunhas são chamadas a } \\
\text { falar em três momentos distintos } \\
\text { (interrogatório, audiência para } \\
\text { oitiva de testemunhas, audiência de } \\
\text { julgamento - júri). }\end{array}$ \\
\hline $\begin{array}{l}\text { Fim maior do } \\
\text { processamento }\end{array}$ & $\begin{array}{l}\text { Acordo entre acusação e defesa } \\
\text { sobre o que ocorreu: em regra, } \\
\text { o encerramento do caso ocorre } \\
\text { após a negociação entre os atores } \\
\text { do sistema de justiça criminal e o } \\
\text { próprio acusado, mas de acordo com } \\
\text { as características do caso, e não de } \\
\text { acordo com regras codificadas que } \\
\text { determinam como o caso deve ser } \\
\text { encerrado. }\end{array}$ & $\begin{array}{l}\text { Busca da verdade real organizada } \\
\text { pelo juiz: apenas quem detém o } \\
\text { conhecimento especializado do } \\
\text { direito pode dizer como o caso } \\
\text { deve se encerrar - se por acordo ou } \\
\text { por sentença. A sentença pode ser } \\
\text { construída por cidadãos (júri), mas } \\
\text { apenas nos casos previstos em lei e } \\
\text { se o juiz entender que essa é a melhor } \\
\text { forma de encerrar o caso. }\end{array}$ \\
\hline $\begin{array}{l}\text { Possibilidade de } \\
\text { julgamento pelo júri }\end{array}$ & $\begin{array}{l}\text { Direito subjetivo do acusado: o júri } \\
\text { apenas ocorre quando o acusado se } \\
\text { diz inocente e quer, pelo julgamento } \\
\text { do júri, se proteger da acusação que o } \\
\text { Estado lhe faz. }\end{array}$ & $\begin{array}{l}\text { Determinado pelo Código de } \\
\text { Processo Penal: o júri é procedimento } \\
\text { reservado para julgamento dos casos } \\
\text { de crimes dolosos contra a vida, não } \\
\text { sendo admitido em outros casos. }\end{array}$ \\
\hline
\end{tabular}

Fonte: Ribeiro (2009). 
A apresentação das características de cada sistema é importante na medida em que o estudo comparado do direito não pode ser uma questão de transformar diferenças concretas em semelhanças abstratas; também não pode ser uma questão de localizar fenômenos idênticos disfarçados sob nomes diferentes. $\mathrm{O}$ estudo comparado do direito pode e deve ser uma tentativa de compreender como as características de um tipo de sensibilidade jurídica ${ }^{2}-$ em termos de pressuposições, preocupações e estruturas de ação - se fazem presentes em outros sistemas valendo-se do uso de características de outra sensibilidade jurídica (Geertz, 1975: 325).

Nesse sentido, a proposta, neste artigo, é descrever como os sistemas de justiça criminal norte-americano e brasileiro administram o tempo de um processo criminal e quais são as circunstâncias que, em cada realidade, contribuem para o aumento ou para a redução desse tempo.

\section{O tempo da justiça criminal nos EUA}

De acordo com Siegel e Senna (2007), nos Estados Unidos da América, a polêmica em torno do tempo despendido pelos sistemas judiciais no processamento de um conflito, seja no meio acadêmico, seja na sociedade, tornou-se evidente quando do julgamento do caso Klopfer vs. North Carolina em 1967.

Nesse caso, Klopfer sentia-se vencido por um promotor que, incapaz de conseguir sua condenação em um primeiro julgamento, decidiu suspender a acusação indefinidamente. Klopfer, o réu, pressionou a justiça para obter um julgamento ou um acordo mais rapidamente. Sem sucesso, ele questionou que a decisão do promotor em processá-lo indefinidamente feria a sexta emenda da Constituição norte-americana, a qual garantia o direito a um julgamento rápido para todos os indivíduos.

No julgamento, a Suprema Corte estabeleceu que um promotor não poderia processar um indivíduo, indefinidamente, sem fornecer uma razão para agir dessa maneira. Na exposição de motivos dessa interpretação, foi dito que o direito ao julgamento rápido deveria ser efetivado em todos os casos, na medida em que apenas dessa forma seria possível: 1) aumentar a credibilidade no processo, fazendo com que o caso pudesse ser apresentado ao tribunal o mais rápido possível; 2) evitar que os acusados permanecessem

2 Entendida como a maneira pela qual as instituições jurídicas traduzem uma linguagem da imaginação para uma linguagem da decisão, criando, assim, um senso de justiça específico. 
presos por um tempo superior ao necessário; 3 ) afastar a excessiva publicidade dos tribunais que, muitas vezes, apresentam essas instâncias como pouco efetivas, dado que excessivamente morosas; 4) evitar que os promotores de justiça viessem a impetrar recursos desnecessários; e 5) evitar qualquer tipo de demora que pudesse afetar a habilidade do acusado em se defender (Siegel e Senna, 2007).

A grande questão apresentada no julgamento do caso Klopfer vs. North Carolina foi, portanto, compreender o que deveria ser entendido como um processamento rápido. A resposta a esse questionamento ocorreu apenas em 1974, após o julgamento do caso Barker vs. Wingo Factors. Esse caso motivou o Congresso americano a publicar, nesse ano, uma interpretação da sexta emenda constitucional.

Essa interpretação foi denominada Federal Speedy Trial Act e estabelecia que o tempo para a averiguação da autoria e da materialidade do delito e, por conseguinte, do apontamento de um suspeito (indictment) não poderia ser superior a 30 dias. Imediatamente após a acusação de um suspeito, o processamento (trial) deveria ser encerrado em até 70 dias, totalizando 100 dias (Listokin, 2007).

No entanto, essa solução "mágica" foi amplamente criticada por advogados, promotores, juízes e cientistas sociais. Na perspectiva desses atores, o problema era que esse tipo de solução (publicação de uma interpretação que fixa o prazo do processo em um determinado número de dias) não seria capaz de alterar as práticas cotidianas dos tribunais. $\mathrm{O}$ efeito perverso dessa medida poderia ser, portanto, levar a um maior descrédito dos tribunais, dada a pouca probabilidade de estes respeitarem o novo "limite" temporal. O entendimento era de que a mudança efetiva no tempo de processamento poderia apenas ocorrer se os operadores compreendessem quais eram os determinantes do tempo e, assim, auxiliassem na formulação de políticas públicas que visassem exatamente ao enfrentamento desse problema (Talarico, 1984).

Uma das primeiras pesquisas de fôlego realizadas sobre o tema foi o survey empreendido pelo National Center for State Courts (NCSC), cuja análise buscava compreender os determinantes do tempo de processamento dos tribunais cíveis e criminais em diversas regiões dos EUA. Os resultados finais dessa análise demonstraram como principais fatores que explicavam a variação do tempo de processamento das demandas criminais os que são apresentados no Quadro 2 a seguir. 


\section{Quadro 2: Principais variáveis que explicam a variação do tempo de processamento das causas criminais pelos EUA (1976)}

\begin{tabular}{|c|c|}
\hline Variável & Importância \\
\hline $\begin{array}{l}\text { Prisão durante o } \\
\text { processo }\end{array}$ & $\begin{array}{l}\text { A prisão durante o processo reduz o tempo de duração deste porque: 1) o réu } \\
\text { deseja sair logo da prisão; 2) o estado norte-americano não deseja ser } \\
\text { processado por manter o réu na prisão por um prazo além do necessário. }\end{array}$ \\
\hline $\begin{array}{l}\text { Recursos para a } \\
\text { Suprema Corte }\end{array}$ & $\begin{array}{l}\text { Especialmente nos casos que contam com advogado particular e nos quais } \\
\text { o réu está em liberdade enquanto o processo tramita, os recursos são usados } \\
\text { especificamente com o expediente de protelar a decisão. Ou seja, considerando } \\
\text { que o réu possui o direito de apelar para as últimas instâncias, ele o faz } \\
\text { sabendo que tal ato apenas resultará no retardo da decisão. }\end{array}$ \\
\hline $\begin{array}{l}\text { Complexidade } \\
\text { do caso ou } \\
\text { procedimentos } \\
\text { aplicáveis a este }\end{array}$ & $\begin{array}{l}\text { Casos que incluem júri popular tendem a demandar mais tempo pela própria } \\
\text { complexidade da causa. Segundo Church Jr. et al. (1978), processos que } \\
\text { possuem esse tipo de procedimento duram, em média, duas semanas a mais do } \\
\text { que os processos julgados pelo juiz singular ou os que se encerram por meio da } \\
\text { plea bargaining (acordos entre advogados, promotores e juízes para punição e } \\
\text { encerramento do caso sem a promulgação de uma sentença). }\end{array}$ \\
\hline $\begin{array}{l}\text { Atuação de } \\
\text { advogados públicos } \\
\text { no processo }\end{array}$ & $\begin{array}{l}\text { A presença de advogados públicos contribuiria para a menor duração do } \\
\text { processo na medida em que eles, em razão do excesso de trabalho, não } \\
\text { poderiam se dedicar à causa sobremaneira, tal como o fazem os advogados } \\
\text { particulares. Um reflexo direto dessa não dedicação à causa seria o pequeno } \\
\text { número de recursos impetrados. Esse fato, por si só, implicaria a redução do } \\
\text { prazo de duração do processo, já que o desejo do advogado público é encerrar } \\
\text { o processo o mais rápido possível, algo que no sistema de justiça criminal } \\
\text { americano se reflete na realização de acordos em vez da continuidade do caso } \\
\text { até a fase de sentença. }\end{array}$ \\
\hline $\begin{array}{l}\text { Presença de } \\
\text { advogados } \\
\text { particulares no } \\
\text { processo }\end{array}$ & $\begin{array}{l}\text { Os advogados particulares recebem por hora trabalhada e, dessa forma, quanto } \\
\text { mais tempo o processo demandar, maiores serão seus honorários. Além disso, } \\
\text { em diversas circunstâncias, os advogados são contratados para garantir que o } \\
\text { tempo de duração do processo seja o maior possível, de tal modo que o caso } \\
\text { seja descolado do calor dos acontecimentos e o réu possa receber uma punição } \\
\text { menos severa. }\end{array}$ \\
\hline $\begin{array}{l}\text { Lugar do } \\
\text { processamento da } \\
\text { causa }\end{array}$ & $\begin{array}{l}\text { Como nos EUA cada estado tem liberdade para estabelecer quais são os } \\
\text { procedimentos a serem aplicados quando da lesão ou ameaça de lesão a um } \\
\text { determinado bem jurídico, a pesquisa verificou que essa diferenciação de } \\
\text { procedimentos é também responsável pelas diferenças no tempo despendido } \\
\text { para o processamento de uma demanda criminal de mesma natureza. }\end{array}$ \\
\hline $\begin{array}{l}\text { Tempo de duração } \\
\text { da causa nos anos } \\
\text { pretéritos }\end{array}$ & $\begin{array}{l}\text { Uma constatação bastante interessante da pesquisa de Church Jr. et al. diz } \\
\text { respeito à inflexão da curva do tempo demandado para o processamento da } \\
\text { causa ao longo dos anos. Segundo os pesquisadores, o tempo de processamento } \\
\text { nos anos anteriores é um importante preditor desse tempo nos anos vindouros. }\end{array}$ \\
\hline
\end{tabular}

Fonte: Church Jr. et al. (1978).

Swigert e Farrell (1980) analisaram a informação de 50\% de todos os homicídios dolosos que resultaram em condenação entre 1955 e 1973 em uma grande jurisdição urbana nos Estados Unidos. Os resultados indicaram que os preditores mais importantes do tempo de processamento foram a liberdade dos réus durante o processo e o fato de o réu ser de cor branca, sendo que ambos atuavam como causas de extensão do tempo de processamento. Ou seja, os réus que gozavam de liberdade provisória e que eram de cor branca tendiam a ter um processo mais demorado do que réus mantidos em custódia ou de cor escura. 
Neubauer e Ryan (1982), por sua vez, testaram a ideia de que as características dos envolvidos têm um papel importante na determinação do tempo de processamento. Os resultados da pesquisa quantitativa indicaram que: 1) crimes qualificados demandam mais tempo para serem processados do que crimes comuns; 2) a existência de recursos à segunda instância contribui para o prolongamento do caso em termos temporais; 3 ) a custódia do réu reduz em $60 \%$ o tempo de processamento; 4) o advogado privado, por sua vez, aumenta em 30\% esse tempo. No que se refere às características pessoais do réu (sexo, idade, grau de escolaridade e renda), apesar de importantes para o controle, não influenciavam no tempo de duração. Uma explicação lançada para esse fenômeno foi o fato de essas variáveis representarem o mesmo tipo de característica representado pela liberdade provisória e pela presença de advogado privado. Isso porque, em certa medida, a presença ou a ausência dessas variáveis indica a capacidade socioeconômica do réu para manejar determinados mecanismos de administração da justiça em cada caso concreto.

Em artigo publicado um ano depois, Neubauer (1983) questionou que o problema principal das pesquisas conduzidas nesse campo, até aquele momento, estava relacionado à ausência de comparação entre o tempo despendido por cada uma das agências encarregadas de processar um determinado crime. Sua perspectiva era a de que cada agência do sistema de justiça criminal possui um sistema de crenças, valores e atitudes diferenciados, contribuindo de maneira distinta para a duração global do processo. Assim, é de esperar que atrasos em uma fase impliquem atrasos ainda maiores em outras, o que não ocorre necessariamente quando se considera, por exemplo, uma terceira agência desse sistema.

Usando os dados de quatro tribunais distintos (Providence, Dayton, Las Vegas e Detroit), Neubauer pôde dividir o tempo de duração do processo em três fases específicas (antes do processo - investigação policial, acusação e julgamento). Com isso, constatou que a fase da promotoria pública é a que possui maior peso no total do tempo despendido no processamento de um delito. Uma das possíveis explicações para esse fenômeno diz respeito ao fato de ser nessa fase que os acordos entre defensores e promotores têm lugar, visando alcançar uma pena mais branda em vez do processo criminal completo.

Por outro lado, a pesquisa demonstrou ainda que a duração longa da fase da promotoria pública explicaria o porquê da duração reduzida (ou mesmo da inexistência) da fase judicial. Em outras palavras, se a negociação na fase da promotoria pública é eficiente, não há que se falar em fase judicial, já que o processo será encerrado pela via de acordos, e não por meio de sentenças formais.

Na segunda parte de seu estudo, Neubauer se concentrou na compreensão de quais eram os fatores que poderiam explicar as diferenças de tempo de 
processamento entre os quatro tribunais. Entre as principais variáveis que apareceram como estatisticamente significantes, tem-se as seguintes: 1) incidente de insanidade mental; 2) não comparecimento do réu nos interrogatórios ou audiências; e 3) ano no qual o processo foi iniciado (que, na perspectiva do autor, era um representante dos atrasos passados do próprio tribunal).

Luskin e Luskin (1986) analisaram os dados oficiais referentes aos casos criminais encerrados em Detroit entre abril de 1976 e março de 1978 para compreender os determinantes da variação do tempo dos processos criminais. Dentre os principais resultados encontrados pelos autores, destacam-se os apresentados no Quadro 3.

\section{Quadro 3: Principais variáveis que explicam o tempo de processamento das causas criminais iniciadas e encerradas entre abril de 1976 e março de 1978 em Detroit (EUA)}

\begin{tabular}{|c|c|}
\hline Variável & Direção de causalidade entre a variável e o tempo de processamento \\
\hline $\begin{array}{l}\text { Natureza da } \\
\text { defesa }\end{array}$ & $\begin{array}{l}\text { Advogados públicos tendem a dar menos atenção ao caso, fazendo com que este } \\
\text { demande mais tempo para alcançar a fase de sentença. }\end{array}$ \\
\hline $\begin{array}{l}\text { Prisão durante o } \\
\text { processo }\end{array}$ & $\begin{array}{l}\text { Como o réu está preso e a prisão é entendida como um dos piores efeitos do } \\
\text { processo nos EUA, todo o esforço do sistema de justiça criminal é concentrado a } \\
\text { fim de reduzir ao máximo tal efeito. }\end{array}$ \\
\hline $\begin{array}{l}\text { Seriedade do } \\
\text { delito }\end{array}$ & $\begin{array}{l}\text { Quando o réu é acusado de um delito extremamente grave e, por isso, sujeito a pena } \\
\text { de morte, ele possui razões estratégicas para contribuir com a demora do processo } \\
\text { e, com isso, retardar ao máximo a condenação. }\end{array}$ \\
\hline $\begin{array}{l}\text { Condenação } \\
\text { anterior }\end{array}$ & $\begin{array}{l}\text { A condenação anterior atua como elemento de extensão do prazo do processo } \\
\text { porque influi no tamanho e na gravidade da pena. Dessa forma, a menos que o réu } \\
\text { já esteja preso, ele tende a contribuir estrategicamente com a dilação do prazo. }\end{array}$ \\
\hline Natureza do juízo & $\begin{array}{l}\text { Juízos especiais fazem com que o caso demande mais tempo para ser processado } \\
\text { do que casos mais simples, que podem ser julgados diretamente pelo juízo singular. } \\
\text { Isso significa que casos julgados pelo Tribunal do Júri tendem a ser naturalmente } \\
\text { mais longos do que os que se encerram por meio da plea bargaining. }\end{array}$ \\
\hline $\begin{array}{l}\text { Número de } \\
\text { acusados }\end{array}$ & $\begin{array}{l}\text { Quanto maior o número de acusados, maiores os problemas de coordenação e, por } \\
\text { conseguinte, maior o tempo despendido no processamento da causa. }\end{array}$ \\
\hline Provas adicionais & $\begin{array}{l}\text { O pedido de provas adicionais para a supressão de qualquer dúvida quanto aos } \\
\text { indícios de autoria e materialidade resulta em extensão do tempo de processamento. }\end{array}$ \\
\hline $\begin{array}{l}\text { Avaliação } \\
\text { psicológica }\end{array}$ & $\begin{array}{l}\text { O simples pedido de avaliação psicológica implica o deslocamento do réu e, por } \\
\text { conseguinte, o retardo do processo. }\end{array}$ \\
\hline $\begin{array}{l}\text { Ausência do } \\
\text { acusado }\end{array}$ & $\begin{array}{l}\text { A ausência do acusado em qualquer dos atos processuais implica a morosidade, uma } \\
\text { vez que o procedimento tem de ser adiado e, por conseguinte, marcado para outra data. }\end{array}$ \\
\hline $\begin{array}{l}\text { Interrogatório do } \\
\text { acusado }\end{array}$ & $\begin{array}{l}\text { O fato de o acusado não ser interrogado imediatamente ou o fato de ser interrogado } \\
\text { duas vezes em momentos distintos do processo faz com que este seja moroso. }\end{array}$ \\
\hline $\begin{array}{l}\text { Fatores } \\
\text { organizacionais } \\
\text { do Tribunal }\end{array}$ & $\begin{array}{l}\text { A necessidade de revisão dos atos da corte por um tribunal central, o número de } \\
\text { casos que cada tribunal possui para julgar (de anos passados inclusive), a obrigação } \\
\text { de processar o caso dentro do tempo delimitado pela Suprema Corte, a descentrali- } \\
\text { zação da negociação para o nível local (em vez do estadual) e o número de casos } \\
\text { que cada juiz tem obrigação de julgar são fatores que influenciam sobremaneira o } \\
\text { tempo de duração do processo. Em razão da dificuldade de mensuração dos diversos } \\
\text { itens que compõem a variável relacionada à organização do tribunal, Luskin e } \\
\text { Luskin os sistematizaram em apenas uma: se o tribunal possuía ou não casos } \\
\text { antigos (de mais de um ano) aguardando algum ato processual, qualquer que fosse. }\end{array}$ \\
\hline
\end{tabular}

Fonte: Luskin e Luskin (1986). 
Já no fim da década de 1990, para estimar o tempo de processamento, Ostrom e Hanson (1999) utilizaram a informação disponibilizada por alguns tribunais, quais sejam: Albuquerque (Novo México); Austin (Texas); Birmingham (Alabama); Cincinnati (Ohio); Grand Rapids (Michigan); Hackensack (Nova Jersey); Oakland (Califórnia); Portland (Oregon) e Sacramento (Califórnia). Com base nos bancos de dados desses tribunais (com informações sobre todos os casos iniciados durante certo período), os autores amostraram 400 casos encerrados no ano de 1994 para coleta de informações minuciosas não apenas a respeito do caso mas também dos envolvidos. Com essa amostra, foi possível constatar que, em regra, os casos de homicídio demoram mais tempo para ser encerrados. Esses crimes são ainda aqueles em que as características do réu são as que melhor explicam as diferenças em termos do tempo necessário para o processamento criminal. Outras variáveis que apareceram como determinantes do tempo de processamento foram a severidade da ofensa, o método de resolução (julgamento ou acordo) e o estado do réu durante o processo (se em custódia ou em liberdade provisória).

Entre os estudos publicados nos anos subsequentes, tem-se o coordenado por Wilson e Klein (2006), no qual foi analisado o processamento criminal de 342 homens originalmente detidos por violência doméstica dentro da jurisdição da corte de Massachusetts (EUA) entre fevereiro de 1995 e março de 1996. O acompanhamento desses casos permitiu verificar que a condenação prévia por um crime violento na juventude faz com que o tempo de processamento seja reduzido em 64\% em comparação com homens com até 46 anos de idade que nunca haviam sido processados ou condenados pela prática de um delito violento.

O sumário das pesquisas realizadas nos EUA parece apontar que o tempo da justiça criminal é, na realidade, o produto combinado das características legais e processuais do caso, das características dos envolvidos e ainda das características organizacionais do próprio tribunal.

\section{O tempo da justiça criminal no Brasil}

Ao contrário do que ocorre nos Estados Unidos, onde os estudos são realizados considerando determinados tribunais, o pressuposto inicial de estudos dessa natureza no Brasil é a definição do delito a ser estudado, já que infrações diferenciadas podem implicar modalidades distintas de processamento e, por conseguinte, tempos prescritos e efetivados diver- 
$\operatorname{sos}^{3}$. Nesse sentido, é importante enfatizar que a maioria das pesquisas desenvolvidas sobre essa temática tem como foco o delito de homicídio doloso, dada a maior confiabilidade nos dados que os delitos dessa natureza apresentam.

Um dos primeiros estudos desenvolvidos no país foi o de Pinheiro et al. (1999), o qual teve como objetivo analisar os processos de linchamento ocorridos no Brasil entre 1980 e 1989. Seus resultados apontaram para o fato de que a morosidade no processamento dos casos de linchamento pode ser explicada, basicamente, pela presença das seguintes variáveis: requisições de laudos complementares; solicitação de informações a outros órgãos; mandados de citação e intimação não cumpridos. Ou seja, as causas da morosidade processual estão relacionadas a uma série de atividades indispensáveis ao andamento do processo e que, em razão do excesso de formalismos, implicam um tempo demasiado longo para serem cumpridas.

Vargas (2004) analisou todos os boletins de ocorrência de estupro registrados na cidade de Campinas entre 1980 e 1996. A análise estatística demonstrou que são fatores que influenciam o tempo de processamento dos casos de estupro: 1) a idade da vítima, já que réus acusados de estupro de vítimas com até 14 anos de idade têm seus processos tramitando quase quatro vezes mais rápido do que aqueles com vítimas de 14 anos ou mais ${ }^{4}$; e 2) a prisão durante o processo, visto que o fato de o réu ter sido preso nesse momento diminui em cinco vezes o tempo do registro da queixa até a sentença.

Em estudo publicado em 2005, Vargas, Blavatsky e Ribeiro analisaram o tempo de tramitação dos processos de homicídio no Estado de São Paulo valendo-se de duas bases de dados: 1) a da Fundação Seade (Sistema Estadual de Análise de Dados), que possuía as informações oficiais (da polícia e da

3 Esse é o primeiro procedimento a ser realizado por pesquisas que têm como propósito analisar o tempo da justiça criminal brasileira, porque o fluxo de processamento de um delito no âmbito desse sistema obedece a sequências de atos específicos (o que o direito processual penal brasileiro denomina de rito) de acordo com a natureza da infração e o quantum cominado de pena a cada tipo de crime. Apenas para se ter uma ideia da diversidade de procedimentos existentes, tem-se que o rito ordinário é o procedimento aplicável aos crimes cuja pena máxima cominada for igual ou superior a quatro anos de pena privativa de liberdade; o rito sumário, aos crimes cuja pena máxima privativa de liberdade for inferior a quatro anos; e o sumaríssimo, às infrações de menor potencial ofensivo cujas penas máximas não excederem a dois anos, sendo de competência do Juizado Especial Criminal (Jecrim). Esse é ainda o procedimento aplicável às contravenções penais cuja diminuta potencialidade ofensiva faz com que esses delitos sejam processados pelo Jecrim. Por fim, cumpre ressaltar que o rito do Tribunal do Júri é aplicável aos crimes dolosos contra a vida.

4 É importante destacar que a análise de Vargas (2004) se restringiu ao crime de estupro porque esse delito possui regras diferenciadas no que se refere ao tempo de processamento quando a vítima tem menos de 14 anos. Isso porque, nesses casos, de acordo com o art. 224 do Código Penal, há presunção de violência. 
justiça) sobre o processamento de todos os casos de homicídio (simples e dolosos) registrados no Estado de São Paulo e cujo registro inicial na polícia ocorreu entre 1991 e 1998; e 2) a resultante da coleta de informações junto a todos os processos de homicídio doloso (93) cujo arquivamento ocorreu em 2003 na cidade de Campinas. De acordo com as autoras, as variáveis apresentadas no Quadro 4 atuam como preditoras do tempo de processamento do delito de homicídio doloso.

\section{Quadro 4: Principais variáveis que explicam o tempo de processamento do homicídio doloso}

\begin{tabular}{|l|l|}
\hline \multicolumn{1}{|c|}{ Variável } & \multicolumn{1}{|c|}{ Direção de causalidade com o tempo de processamento } \\
\hline Tipo de crime & $\begin{array}{l}\text { Crimes mais graves aumentam o tempo de processamento, pois, em regra, } \\
\text { contam com a presença de advogado particular para utilizar os recursos } \\
\text { processuais protelatórios que podem levar à materialização da prescrição. }\end{array}$ \\
\hline Revelia do réu & $\begin{array}{l}\text { Implica o aumento do tempo, dada a dificuldade dos funcionários judiciais em } \\
\text { se comunicarem com outros cartórios e delegacias de polícia para, dessa forma, } \\
\text { encontrar o réu. }\end{array}$ \\
\hline $\begin{array}{l}\text { Problemas na fase } \\
\text { da polícia }\end{array}$ & $\begin{array}{l}\text { A fase com maior tempo de duração é a do inquérito policial, dada a dificuldade } \\
\text { de obtenção de provas, de demora na realização de perícias e, até mesmo, de } \\
\text { identificação do autor do delito. }\end{array}$ \\
\hline $\begin{array}{l}\text { Adiamento do } \\
\text { julgamento }\end{array}$ & $\begin{array}{l}\text { O adiamento do julgamento, em qualquer fase do processo, faz com que o } \\
\text { tempo de processamento seja aumentado. Advogados particulares manejam } \\
\text { esse instituto nesse sentido, e a ausência de defensores públicos faz com que a } \\
\text { prática termine por ocorrer sucessivas vezes. }\end{array}$ \\
\hline $\begin{array}{l}\text { Dificuldade na } \\
\text { localização de } \\
\text { testemunhas }\end{array}$ & $\begin{array}{l}\text { Implica o aumento do tempo em razão da demora dos tribunais em processarem } \\
\text { as cartas precatórias. }\end{array}$ \\
\hline $\begin{array}{l}\text { Prisão do indivíduo } \\
\text { ao longo de todo } \\
\text { o processo ou em } \\
\text { algum momento } \\
\text { do processo }\end{array}$ & $\begin{array}{l}\text { Trata-se de fator a ser mais bem compreendido, já que, até a sentença } \\
\text { intermediária, os processos correm mais rapidamente para réus presos do que } \\
\text { para réus não presos. Após essa fase, a relação se inverte, passando os réus } \\
\text { presos a ter andamento mais lento em seus processos. }\end{array}$ \\
\hline $\begin{array}{l}\text { Natureza da defesa } \\
\text { Número de } \\
\text { recursos }\end{array}$ & $\begin{array}{l}\text { Advogados particulares fazem com que o processo dure mais, ou para que seu } \\
\text { cliente seja beneficiado com a prescrição, ou para que alcance uma pena menor. } \\
\text { O uso de recursos legalmente previstos visa atender os interesses do acusado } \\
\text { implicar uma punição menor ou mesmo a extinção do processo pelo decurso } \\
\text { do tempo. }\end{array}$ \\
\hline
\end{tabular}

Fonte: Vargas, Blavatsky e Ribeiro (2005).

Batitucci, Cruz e Silva (2006) analisaram uma amostra de processos de homicídios dolosos arquivados no Tribunal de Justiça de Minas Gerais, mas que foram julgados pelos tribunais do júri das comarcas de Belo Horizonte, Ipatinga e Coronel Fabriciano entre 1985 e 2003. Os resultados indicaram que a maior parte do tempo de processamento é referente ao encerramento do inquérito policial. Quando este, já terminado, é devolvido pelo Ministério Público à organização policial para a continuidade das investigações, o tempo 
médio também é estendido. Esses resultados, de acordo com os autores, evidenciavam a falência do modelo investigativo adotado pela Polícia Civil em Minas Gerais e sua incapacidade institucional de fazer frente às demandas dos casos de homicídio doloso, sendo esse o principal aspecto que contribuiria para o aumento do tempo de duração de um processo penal.

Ruschel (2006) analisou os casos de homicídio doloso julgados em primeiro grau em 2004, na cidade de Florianópolis, e pôde constatar que a presença de cartas precatórias e de recursos de habeas corpus, bem como de outros pleitos ao juiz, os quais prolongaram a duração do processo penal, contribui para dar ensejo à morosidade. Casos com recursos aos tribunais superiores são os que demandam mais tempo, pois, para tanto, são necessários de um a nove meses para a volta da resposta ao fórum, acrescidos de mais dois meses para agendamento de uma nova data para o julgamento na concorrida agenda do juiz.

Ribeiro e Duarte (2008) analisaram 624 casos de homicídio doloso cujo processo fora iniciado e encerrado nos quatro tribunais do júri da cidade do Rio de Janeiro entre 2000 e 2007, e constataram que o flagrante atua como fator de redução do tempo. Por outro lado, o fato de o caso se encerrar com uma condenação atua como fator de extensão do tempo global de processamento do caso. Já outras variáveis (homicídio qualificado, homicídio praticado com concurso de agentes e presença de testemunhas) não interferiram expressivamente no tempo de duração do processo.

Analisando 131 casos de homicídio doloso ocorridos entre 1977 e 1992, e cujo arquivamento do processo criminal se deu em um dos quatro tribunais do júri do Fórum Central da cidade do Rio de Janeiro em 1996, Ribeiro (2009) constatou que, controlando pelas características dos envolvidos, pelas características legais e processuais, as variáveis idade do réu, sexo da vítima, presença de assistente da acusação, presença de arma de fogo e presença de flagrante são as que melhor explicam a variação do tempo da justiça criminal brasileira. Se a vítima é do sexo feminino, o tempo de duração de seu processo é inferior quando comparado ao tempo de duração de processos cuja vítima é do sexo masculino. Por outro lado, a presença de assistente da acusação reduz o tempo de duração do processo penal em comparação com os casos nos quais essa figura não se faz presente. Já a presença de arma de fogo aumenta o tempo de processamento em comparação a crimes cometidos com outros instrumentos. Por fim, a presença de flagrante reduz a duração do processo em comparação a casos em que a investigação policial é iniciada por portaria.

Todas essas pesquisas parecem indicar que, no Brasil, as variáveis que contribuem para o aumento do tempo do processo penal são: 1) o fato de o 
crime ter sido praticado na forma qualificada, e não na forma simples; 2) a excessiva burocratização dos procedimentos judiciais; 3 ) a presença de liberdade provisória durante o processo em vez da prisão em flagrante; 4) a existência de cartas precatórias; 5) os problemas enfrentados durante a fase de investigação; e 6) os recursos para os tribunais superiores.

\section{Conectando os resultados encontrados nos EUA e no Brasil}

A proposta aqui foi apresentar as pesquisas já realizadas sobre os determinantes do tempo da justiça criminal nos Estados Unidos da América e no Brasil dentro de uma perspectiva comparada. Assim, este texto teve início com uma discussão dos pressupostos do uso do método comparado no caso de estudos sobre o funcionamento do sistema de justiça criminal. A perspectiva da primeira seção foi apresentar, em linhas gerais, as diferenças estruturais existentes entre os sistemas brasileiro e norte-americano, as quais inviabilizam comparações diretas ou que tenham como objetivo denotar que sistema é mais eficiente no sentido de processar determinada demanda. Exatamente por isso, o tempo da justiça criminal, ou o número de dias necessários para o processamento de uma infração em cada localidade, não foi discutido ou contrastado.

No entanto, se o tempo de processamento em si não pôde ser comparado, na medida em que este é uma função da forma de organização do sistema, as variáveis que explicam sua extensão em uma localidade podem ser utilizadas para salientar fenômenos muitas vezes não considerados em outro contexto. Com a inclusão dessa perspectiva, é possível verificar determinados padrões quanto ao funcionamento do sistema de justiça criminal em cada realidade (ver Quadro 5).

O Quadro 5 parece denotar que, em boa medida, os estudos realizados no Brasil apontam para o fato de que o tempo da justiça criminal é o resultado combinado das mesmas variáveis que explicam o tempo da justiça criminal nos EUA. Por outro lado, denota ainda que dimensões importantes na análise do tempo da justiça criminal, de acordo com as pesquisas realizadas nos EUA, ainda não foram incorporadas pelas pesquisas nacionais. Nesse ponto, as variáveis organizacionais que ainda permanecem pouco exploradas pelos estudos feitos no Brasil têm particular destaque.

Esse resultado indica, portanto, que a inclusão de novas dimensões relevantes para a compreensão do tempo de processamento no sistema de justiça criminal dos EUA - nas análises relacionadas a esse mesmo objeto no que diz respeito ao sistema de justiça criminal no Brasil pode, sim, lançar novas luzes ao entendimento do fenômeno, dadas as regularidades anteriormente constatadas. 
Quadro 5: Sumário das variáveis apontadas pelas pesquisas realizadas nos EUA e no Brasil como explicativas do tempo da justiça criminal, de acordo com o efeito que cada qual possui sobre o tempo global de processamento em cada uma dessas realidades

\begin{tabular}{|c|c|c|}
\hline $\begin{array}{l}\text { Variáveis apontadas pelos estudos como } \\
\text { causas da morosidade processual }\end{array}$ & EUA & Brasil \\
\hline \multicolumn{3}{|l|}{ Características dos envolvidos } \\
\hline Réus de cor branca & Aumenta o tempo & Não testado \\
\hline Réus do sexo masculino & Não interfere & Aumenta o tempo \\
\hline Réus jovens & Aumenta o tempo & Não testado \\
\hline Vítimas de cor branca & Aumenta o tempo & Não testado \\
\hline Vítimas do sexo masculino & Aumenta o tempo & Não testado \\
\hline Vítimas jovens & Aumenta o tempo & Diminui o tempo \\
\hline \multicolumn{3}{|l|}{ Características processuais } \\
\hline Uso de arma de fogo & Aumenta o tempo & Não testado \\
\hline Presença de advogado particular & Aumenta o tempo & Aumenta o tempo \\
\hline $\begin{array}{l}\text { Ausência do acusado em quaisquer atos do } \\
\text { processo }\end{array}$ & Aumenta o tempo & Aumenta o tempo \\
\hline Lugar do processamento da causa & Aumenta o tempo & Não testado \\
\hline Grande número de acusados & Aumenta o tempo & Não testado \\
\hline Ausência de interrogatório imediato do réu & Aumenta o tempo & Não testado \\
\hline \multicolumn{3}{|l|}{ Características legais } \\
\hline $\begin{array}{l}\text { Tipo de crime (crimes mais graves ou cujo } \\
\text { código apresente penas mais elevadas) }\end{array}$ & Aumenta o tempo & Não testado \\
\hline $\begin{array}{l}\text { Crimes qualificados (casos mais } \\
\text { complexos) }\end{array}$ & Aumenta o tempo & Aumenta o tempo \\
\hline Julgamento do caso por um Juízo Especial & Diminui o tempo & Aumenta o tempo \\
\hline Liberdade provisória & Aumenta o tempo & Aumenta o tempo \\
\hline Pedido de perícia médica & Aumenta o tempo & Aumenta o tempo \\
\hline Pedido de provas adicionais & Aumenta o tempo & Aumenta o tempo \\
\hline Presença de cartas precatórias & Aumenta o tempo & Aumenta o tempo \\
\hline Recursos para os tribunais superiores & Aumenta o tempo & Aumenta o tempo \\
\hline Condenação do acusado por crime anterior & Aumenta o tempo & Não testado \\
\hline \multicolumn{3}{|l|}{ Características temporais } \\
\hline $\begin{array}{l}\text { Problemas no andamento da fase de } \\
\text { investigação }\end{array}$ & Aumenta o tempo & Aumenta o tempo \\
\hline \multicolumn{3}{|l|}{ Caracteristicas do Tribunal } \\
\hline $\begin{array}{l}\text { Excessiva burocratização dos procedimentos } \\
\text { judiciais }\end{array}$ & Aumenta o tempo & Aumenta o tempo \\
\hline $\begin{array}{l}\text { Ausência de órgãos específicos destinados a } \\
\text { monitorar o tempo dos tribunais }\end{array}$ & Aumenta o tempo & Não testado \\
\hline $\begin{array}{l}\text { Insuficiência de infraestruturas judiciárias e de } \\
\text { recursos humanos }\end{array}$ & Aumenta o tempo & Não testado \\
\hline Aumento considerável de litígios & Aumenta o tempo & Não testado \\
\hline $\begin{array}{l}\text { Natureza da relação pessoal existente entre } \\
\text { promotores, defensores e juízes }\end{array}$ & Aumenta o tempo & Não testado \\
\hline
\end{tabular}

Dados da pesquisa realizada pela autora. 
Por outro lado, um ponto que indica a importância de se considerar as características que estruturam o funcionamento do sistema quando da construção de uma análise comparada é o peso que cada fase possui para o cômputo global do tempo de processamento. Por exemplo, como nos EUA o fim maior do processo é a construção de acordos entre acusação e defesa sobre o que ocorreu, é de esperar, como constatado por Neubauer (1983), que a fase mais longa do processamento criminal norte-americano seja a da promotoria, porque é nesse momento que os acordos são construídos.

Dessa forma, se o fim maior do processamento no cenário brasileiro é a busca da verdade real ${ }^{5}$, é de esperar que as fases relacionadas à coleta de informações sejam as que contribuem para a maior extensão do tempo de processamento. Essa é a conclusão de Batitucci, Cruz e Silva (2006), que constataram que o maior problema na administração do tempo da justiça criminal no processamento dos homicídios dolosos parece ser exatamente o excesso de prazo decorrente da requisição de laudos e de perícias que podem ser utilizados pelo juiz para fundamentar sua decisão ou que podem ser solicitados por ele.

Em razão dessas especificidades, fica evidente que o método comparado pode viabilizar o maior conhecimento de uma realidade com base no uso de categorias que explicam o funcionamento do mesmo fenômeno em outra realidade. Entretanto, exatamente para se evitar que semelhanças abstratas se tornem diferenças concretas, é preciso explicitar quais são as características estruturais e estruturantes de cada sistema que devem ser consideradas quando da operacionalização de estudos dessa natureza.

Outro ponto que parece evidenciar a importância dessa ressalva é o pressuposto que estrutura os estudos sobre o tempo do sistema de justiça criminal no Brasil. Nesse contexto, o primeiro procedimento adotado é a escolha do delito a ser analisado, já que as regras legais do Brasil estabelecem formas e tempos de processamento diferenciados (ritos), de acordo com o delito em análise ${ }^{6}$. Desse modo, como o rito, por si só, implica uma maior ou menor duração do tempo de processamento, bem como a realização de uma série de atos processuais que não necessariamente serão realizados quando do processamento de outros delitos, essa é uma variável a ser considerada quando da operacionalização da pesquisa.

5 Tal como destacado no estudo de Kant de Lima (1995) sobre o funcionamento do sistema de justiça criminal.

6 Por exemplo, atualmente (após a edição das leis 11.719/08 e 11.689/08), para os crimes comuns, encontram-se prescritos 150 dias como prazo de processamento; para os crimes dolosos, 315 dias. 
Nos EUA, por sua vez, crimes distintos são submetidos a processamentos semelhantes, e, assim, é possível considerar todos os delitos em conjunto para compreender o tempo de duração de um processo. Inclusive, em análises realizadas no âmbito desse sistema de justiça criminal, um dos determinantes do tempo de processamento é exatamente a modalidade de crime em questão. Ostrom e Hanson (1999), por exemplo, constataram que os casos de homicídio são aqueles em que as características do réu são as que melhor explicam as diferenças em termos do tempo necessário para o processamento criminal, algo que não ocorre com outros delitos.

Portanto, em que pesem as tradições jurídicas diferenciadas do Brasil e dos Estados Unidos, o contraste dos estudos de uma localidade com os de outra parece denotar que alguns fenômenos são importantes para o entendimento do tempo da justiça criminal desde uma perspectiva global. Contudo, para que esses fenômenos possam ser prontamente identificados, faz-se indispensável conhecer as características da ossatura institucional de cada sistema.

\section{Referências}

BATITUCCI, E.C.; CRUZ, M.V.; SILVA, B.I. Fluxo do crime de homicídio no sistema de justiça criminal de Minas Gerais. In: Encontro da Associação Nacional de PósGraduação e Pesquisa em Ciências Sociais (Anpocs), 30., Caxambu, 2006. Anais... Caxambu: Anpocs, 2006.

BLOCH, M. Comparaison. Revue de synthèse historique LXIX (boletim anexo), 1930. p. 31-9.

CHURCH JR., T.W. et al. Justice delayed: the pace of litigation in urban trial courts. Williamsburg, VA: National Center for State Courts, 1978.

GEERTZ, C. The interpretation of cultures: selected essays. London: Hutchinson, 1975.

KANT DE LIMA, R. Da inquirição ao júri, do trial by jury à plea bargaining: modelos para produção da verdade e negociação da culpa em uma perspectiva comparada Brasil/Estados Unidos. Tese (Concurso de Professor Titular em Antropologia) - Departamento de Antropologia, Universidade Federal Fluminense, Niterói, RJ, 1995.

LISTOKIN, Y. Crime and (with a lag) punishment: the implications of discounting for equitable sentencing. American Criminal Law Review, v. 44, n. 1, 2007.

LOUNDO, D.; MISSE, M. (orgs.). Diálogos tropicais: Brasil e Índia. Rio de Janeiro: Ed. da UFRJ, 2003.

LUSKIN, M.L.; LUSKIN, R.C. Why so fast, why so slow? Explaining case processing time. Journal of Criminal Law and Criminology, v. 77, n. 1, 1986.

MERRYMAN, J.H. The civil law tradition: an introduction to the legal systems of Western Europe and Latin America. Stanford: Stanford University Press, 1969. 
NEUBAUER, D.W. Improving the analysis and presentation of data on case processing time. Journal of Criminal Law and Criminology, v. 74, n. 4, 1983.

NEUBAUER, D.W.; RYAN, J. P. Criminal courts and the delivery of speed justice: the influence of case and defendant characteristics. Justice System Journal, v. 7, n. 2, 1982.

OSTROM, B.J.; HANSON, R.A. Efficiency, timeliness, and quality: a new perspective from nine state criminal trial courts. Williamsburg, VA: National Center for State Courts/National Institute of Justice/The State Justice Institute, 1999.

PAKES, F.J. Comparative criminal justice. Cullompton/Portland: Willan, 2004.

PINHEIRO, P.S. et al. Continuidade autoritária e construção da democracia. São Paulo: Núcleo de Estudos da Violência/USP, 1999.

RIBEIRO, L.M.L. Administração da justiça criminal na cidade do Rio de Janeiro: uma análise dos casos de homicídio. Tese (Doutorado em Sociologia) - Instituto Universitário de Pesquisas do Rio de Janeiro (Iuperj), Rio de Janeiro, 2009.

RIBEIRO, L.M.L.; DUARTE, T.L. Padrões de seleção no processamento dos homicídios dolosos: o tempo dos casos julgados pelo Tribunal de Justiça do Rio de Janeiro entre os anos 2000 e 2007. In: Encontro da Associação Nacional de Pós-Graduação e Pesquisa em Ciências Sociais (Anpocs), 32., Caxambu, 2008. Anais... Caxambu: Anpocs, 2008.

RUSCHEL, A. J. Análise do tempo dos processos penais de homicídio no Fórum de Justiça de Florianópolis julgados em 2004. Dissertação (Mestrado em Antropologia Social) - Universidade Federal de Santa Catarina (UFSC), Florianópolis, 2006.

SAPORI, L.F. A justiça criminal brasileira como um sistema frouxamente articulado. In SLAKMON, C.; MACHADO, M.R.; BOTTINI, P.C. (orgs.). Novas direções na governança da justiça e da segurança. Brasília, DF: Ministério da Justiça, 2006.

SICA, L. Bases para o modelo brasileiro de justiça restaurativa. In SLAKMON, C.; MACHADO, M. R.; BOTTINI, P. C. (orgs.). Novas direções na governança da justiça e da segurança. Brasília, DF: Ministério da Justiça, 2006.

SIEGEL, L.J.; SENNA, J.J. Essentials of criminal justice. Belmont, CA: Thomson Higher Education, 2007.

SWIGERT, V.L.; FARRELL, R.A. Speedy trial and the legal process. Law And Human Behavior, v. 4, n. 3, 1980.

TALARICO, S.M. The trials and tribulations of court reform: a review essay. Justice Quarterly, v. 1, n. 1, 1984.

THEML, N.; BUSTAMANTE, R. História comparada: olhares plurais. Revista de História Comparada, v. 1, n. 1, jun./2007.

VARGAS, J.D. Estupro: que justiça? Fluxo do funcionamento e análise do tempo da justiça criminal para o crime de estupro. Tese (Doutorado em Sociologia) - Instituto Universitário de Pesquisas do Rio de Janeiro (Iuperj), Rio de Janeiro, 2004.

VARGAS, J.D.; BLAVATSKY, I.; RIBEIRO, L.M.L. Metodologia de tratamento do tempo e da morosidade processual na justiça criminal. Brasília, DF: Ministério da Justiça, 2005. 
WERNECK VIANNA, L. Poder Judiciário, “positivação" do direito natural e política. Estudos Históricos, v. 9, n. 18, 1996.

WILSON, D.; KLEIN, A. A longitudinal study of a cohort of batterers arraigned in a Massachusetts District Court 1995 to 2004. Massachusetts: The National Institute of Justice, 2006. 